\title{
Retrospective study testing next generation sequencing of selected cancer-associated genes in resected prostate cancer
}

\author{
Marco Lo Iacono ${ }^{1, *}$, Consuelo Buttigliero ${ }^{1, *}$, Valentina Monica ${ }^{1, *}$, Enrico Bollito ${ }^{1}$, \\ Diletta Garrou ${ }^{1}$, Susanna Cappia ${ }^{1}$, Ida Rapa ${ }^{1}$, Francesca Vignani ${ }^{1}$, Valentina \\ Bertaglia ${ }^{1}$, Cristian Fiori $^{1}$, Mauro Papotti ${ }^{1}$, Marco Volante ${ }^{1}$, Giorgio V. Scagliotti ${ }^{1}$, \\ Francesco Porpiglia ${ }^{1}$, Marcello Tucci ${ }^{1}$ \\ ${ }^{1}$ University of Turin, Department of Oncology, Orbassano, Italy \\ *All these Authors equally contributed to the experimental study \\ Correspondence to: Consuelo Buttigliero, e-mail: consuelo.buttigliero@gmail.com \\ Keywords: next generation sequencing, prostate cancer, precision medicine, genetic characterization, prognostic factors \\ Received: November 17, $2015 \quad$ Accepted: January 25, $2016 \quad$ Published: February 12, 2016
}

\section{ABSTRACT}

Purpose: Prostate cancer (PCa) has a highly heterogeneous outcome. Beyond Gleason Score, Prostate Serum Antigen and tumor stage, nowadays there are no biological prognostic factors to discriminate between indolent and aggressive tumors.

The most common known genomic alterations are the TMPRSS-ETS translocation and mutations in the PI3K, MAPK pathways and in p53, RB and c-MYC genes.

The aim of this retrospective study was to identify by next generation sequencing the most frequent genetic variations (GVs) in localized and locally advanced PCa underwent prostatectomy and to investigate their correlation with clinical-pathological variables and disease progression.

Results: Identified non-synonymous GVs included TP53 p.P72R (78\% of tumors), two CSFR1 SNPs, rs2066934 and rs2066933 (70\%), KDR p.Q472H (67\%), KIT p.M541L (28\%), PIK3CA p.I391M (19\%), MET p.V378I (10\%) and FGFR3 p.F384L/p.F386L (8\%). TP53 p.P72R, MET p.V378I and CSFR1 SNPs were significantly associated with the HI risk group, TP53 and MET variations with T $\geq T 2 c$. FGFR3 p.F384L/p.F386L was correlated with T $\leq$ T2b. MET p.V378I mutation, detected in $20 \%$ of HI risk patients, was associated with early biochemical recurrence.

Experimental design: Nucleic acids were obtained from tissue samples of $\mathbf{3 0}$ high (HI) and 30 low-intermediate (LM) risk patients, according to D'Amico criteria. Genomic DNA was explored with the Ion_AmpliSeq_Cancer_Hotspot_Panel_v.2 including 50 cancer-associated genes. GVs with allelic frequency (AF) $\geq 10 \%$, affecting protein function or previously associated with cancer, were correlated with clinicalpathological variables.

Conclusion: Our results confirm a complex mutational profile in $\mathrm{PCa}$, supporting the involvement of TP53, MET, FGFR3, CSF1R GVs in tumor progression and aggressiveness.

\section{INTRODUCTION}

Prostate cancer (PCa) is the most common type of cancer in men, with nearly 220,000 new cases expected in 2015 in USA [1]. The widespread use of serum prostate specific antigen (PSA) as a screening tool led to the increased frequency of $\mathrm{PCa}$ diagnoses. A subgroup of patients with extremely localized PCa may be potentially over-treated because only a proportion will develop a clinically detectable disease during their lifespan. PCa is extremely heterogeneous, ranging from a chronic indolent illness to an aggressive rapidly fatal malignancy. Beyond the classical prognostic factors of tumor stage (T), PSA level and Gleason score (GS), to date there are no biological prognostic factors able to discriminate between indolent and aggressive tumors. The abovementioned clinical prognostic factors allow clinicians to categorize patients into broad risk groups (low, intermediate and 
high risk) but they incompletely explain the observed heterogeneity of clinical outcome [2]. Moreover, specific pathological assessments as, for instance, the GS is operator-dependent and inter-observer variability has been reported. Therefore, new prognosticators are needed to improve clinician's skill in predicting individual likelihood of each PCa to progress and metastasize.

Advances in sequencing technologies generated a huge amount of data about the mutational events underlying development, progression and treatment response in cancer. Even if the spectrum of genetic alterations in $\mathrm{PCa}$ is heterogeneous, these mutations are more frequently reported in the PI3K and MAPK pathways and in p53, RB and c-MYC genes, all known to affect tumorigenesis in a wide spectrum of tumors, while there are others genetic alterations more specifically reported in $\mathrm{PCa}$ [3]. The vast majority of PCa harbors ETS rearrangements, generally as TMPRSS-ERG fusion [4]. In addition, PTEN and TP53 tumor suppressor genes are deleted in about $20-40 \%$ of $\mathrm{PCa}$ while Speckle-Type POZ Protein mutations occur in about $10 \%$ of the samples $[5,6]$.

In this retrospective study, formalin-fixed, paraffinembedded (FFPE), prostatectomy specimens from 60 patients with localized or locally advanced PCa having clinical annotates were collected. Tumor samples were analyzed by next generation sequencing (NGS) in order to test the most frequent genetic mutations reported in cancers and to investigate their potential correlation with clinical pathological variables and disease progression.

\section{RESULTS}

Sixty cases of localized or locally advanced PCa submitted to radical prostatectomy at San Luigi Gonzaga Hospital (Orbassano, Turin) were retrospectively extracted from an institutional clinical database. Based on PSA, GS and T, using the D'Amico criteria, tumors were categorized as high risk (HI, PSA $>20 \mathrm{ng} / \mathrm{ml}, \mathrm{GS}>7$, $\mathrm{T} 2 \mathrm{c}-\mathrm{T} 3, \mathrm{n}=30$ ) or low-intermediate risk (LM, low risk: PSA $<10 \mathrm{ng} / \mathrm{ml}, \mathrm{GS}<7$, T1-T2a; intermediate risk: PSA: $10-20 \mathrm{ng} / \mathrm{ml}, \mathrm{GS}=7, \mathrm{~T} 2 \mathrm{~b}, \mathrm{n}=30$ ).

Patients' characteristics are shown in Table 1 . Median age was 66 (range: 49-76), median PSA before prostatectomy was $7 \mathrm{ng} / \mathrm{ml}$ (range: $3.2-21$ ); 29 patients (48.3\%) had GS=6, 28 (46.6\%) GS=7 and 3 (5.1\%) had $\mathrm{GS}=8$. TMPRSS2:ERG fusion was found in $14 / 29(48 \%)$ HI patients and in 5/26 LM (19\%). AR expression was detectable in all samples analyzed but was not statistically different between two patient groups $(\mathrm{p}=0.9)$.

Older age ( $>$ median), PSA at diagnosis $>10 \mathrm{ng}$, Gleason Score $\geq 7, T \geq 2 c$, perineural/vascular invasion, pelvic lymphadenectomy, biochemical recurrence and TMPRSS2:ERG translocation were significantly associated with the HI group (Table 1). Gleason Score $\geq 7, T \geq 2 \mathrm{c}$, vascular invasion, pelvic lymphadenectomy and PSA after prostatectomy $>0.02 \mathrm{ng}$ were significantly associated with early progression time. Gleason Score, vascular invasion and PSA after prostatectomy were independent predictors of early progression time (Gleason Score: $\mathrm{p}=0.02, \mathrm{HR}=5.4$ 95\% CI [1.24-23.37], vascular invasion: $\mathrm{p}=0.045$, HR 3.86 95\% CI [1.03-14.5], PSA after prostatectomy: $\mathrm{p} \ll 0.01$, HR $121.495 \%$ CI [17.41847.31]).

\section{CHP2 genetic profile}

DNA was successfully extracted, amplified and sequenced from all samples. Non-synonymous genetic variations (GVs) with allelic frequency $(\mathrm{AF}) \geq 10 \%$ are reported in Figure 1 and complete information for all genes included in analysis are presented in Supplementary Table S1. The most frequent non-synonymous GVs identified were TP53 p.P72R (COSM250061) in 78\% of tumors, followed by two SNPs (rs2066934, rs2066933), within the 3'UTR of the CSFR1 gene in $70 \%$ of tumors, KDR p.Q472H (COSM149673) in 67\%, KIT p.M541L (COSM28026) in 28\%, PIK3CA p.I391M (COSM328028) in 19\%, MET p.V378I (COSM3411512) in 10\% and FGFR3 p.F384L/p.F386L (COSM724,COSM1539830) in $8 \%$. The GVs at TP53 p.P72R, CSFR1 (rs2066934, rs2066933) and MET p.V378I were significantly associated with the HI risk group $(\mathrm{p}=0.027, \mathrm{p}=0.047$ and $\mathrm{p}=0.011$, respectively). Moreover, TP53 p.P72R and MET p.V378I were also correlated to $T \geq T 2 c(p=0.032$ and $\mathrm{p}=0.047$, respectively). Conversely, genetic variation FGFR3 p.F384L/p.F386L was correlated with $\mathrm{T} \leq \mathrm{T} 2 \mathrm{~b}$ $(\mathrm{p}=0.004)$ and KDR p.Q472H with tumors lacking vascular invasion $(\mathrm{p}=0.021)$. Among synonymous $\mathrm{GVs}$ only the FGFR3 SNP rs3135898, found in 11 patients $(18 \%)$, was significantly correlated to the HI group and $\mathrm{T} \geq \mathrm{T} 2 \mathrm{c}$ tumors $(\mathrm{p}=0.042$ and $\mathrm{p}=0.029$, respectively). MET p.V378I mutation, clustered among 6 patients of the HI risk group (20\%), was correlated to early $\mathrm{PCa}$ recurrence ( $p=0.02$, HR $3.5495 \%$ CI [1.38-44.98]). At the multivariable analysis, this mutation was an independent predictor of early recurrence of borderline statistical significance $(\mathrm{p}=0.055$, HR 5.76 95\% CI [0.97-34.31]) (Table 2).

Two groups of tumors were identified according to the CHP2 mutational profile findings: tumors with few non-synonymous GVs and tumors with several GVs in many genes. Independently from the risk class, the second group was associated with high TP53 mutational rate. To assess the robustness of this preliminary observation, the entire group of patients was clustered for "deleterious" or "tolerated" TP53 mutations, using a combination of PolyPhen-2 and SIFT software. These bioinformatic tools apply statistical algorithms based on sequence- and structure- information to predict the effect of GVs on proteins functionality/activity. As shown in Figure 2 and 3, both using the $\geq 10 \%$ and the $\geq 5 \%$ AF filter, patients with a high mutation rate were often included in "TP53 GVs 
Table 1: Clinical pathological features in high and low/intermediate risk prostate cancer patients

\begin{tabular}{|c|c|c|c|c|c|}
\hline & & Tot N (\%) & High (30) & Low/Med (30) & $\begin{array}{c}\text { P value Fisher } \\
\text { Test }\end{array}$ \\
\hline \multirow[t]{3}{*}{ Age (median: 66 Years) } & & & & & $<0.01$ \\
\hline & Under & $30(50)$ & 9 & 21 & \\
\hline & Over & $30(50)$ & 21 & 9 & \\
\hline \multirow[t]{4}{*}{ PSA at diagnosis } & & & & & 0.02 \\
\hline & $\leq 10$ & $46(76.6)$ & 18 & 28 & $(>10 \mathrm{ng})$ \\
\hline & $10-20$ & $10(16.7)$ & 8 & 2 & \\
\hline & $>20$ & $4(6.7)$ & 1 & & \\
\hline \multirow[t]{3}{*}{ PSA post prostatectomy } & & & & & 0.37 \\
\hline & $<0.02$ & $50(83.3)$ & 23 & 27 & \\
\hline & $\geq 0.02$ & $10(16.7)$ & 7 & 3 & \\
\hline \multirow[t]{4}{*}{ Gleason Score } & & & & & $\ll 0.01$ \\
\hline & $<7$ & $28(46.6)$ & 6 & 22 & $(\geq 7)$ \\
\hline & $=7$ & $29(48.3)$ & 21 & 8 & \\
\hline & $>7$ & $3(5.1)$ & 3 & 0 & \\
\hline \multirow[t]{4}{*}{ Tumor Size (T) } & & & & & $\ll 0.01$ \\
\hline & $\mathrm{T} 1-\mathrm{T} 2 \mathrm{a}$ & $16(26.6)$ & 0 & 16 & $(\geq 2 c)$ \\
\hline & $\mathrm{T} 2 \mathrm{~b}$ & $14(23.3)$ & 1 & 13 & \\
\hline & $\mathrm{T} 2 \mathrm{c}-\mathrm{T} 3$ & $30(50)$ & 29 & 1 & \\
\hline \multirow[t]{3}{*}{ Perineural invasion } & & & & & 0.012 \\
\hline & no & $10(16.7)$ & 1 & 9 & \\
\hline & yes & $50(83.3)$ & 29 & 21 & \\
\hline \multirow[t]{4}{*}{ Vascular invasion } & & & & & 0.03 \\
\hline & no & $43(71.7)$ & 18 & 27 & \\
\hline & yes & $13(21.7)$ & 10 & 3 & \\
\hline & missing & $4(6.6)$ & & & \\
\hline \multirow[t]{3}{*}{ Surgical margins } & & & & & 1 \\
\hline & R0 & $53(88.3)$ & 26 & 27 & \\
\hline & R1 & $7(11.7)$ & 4 & 3 & \\
\hline \multirow[t]{3}{*}{ Pelvic Lymphadenectomy } & & & & & $\ll 0.01$ \\
\hline & no & $38(63.3)$ & 10 & 28 & \\
\hline & yes & $22(36.7)$ & 20 & 2 & \\
\hline \multirow[t]{3}{*}{ Biochemical recurrence } & & & & & $<0.01$ \\
\hline & no & $45(75)$ & 17 & 28 & \\
\hline & yes & $15(25)$ & 13 & 2 & \\
\hline \multirow[t]{3}{*}{ ERG:TMPRSS2 } & & & & & 0.03 \\
\hline & no & $41(68.3)$ & 16 & 25 & \\
\hline & yes & $19(31.7)$ & 14 & 5 & \\
\hline
\end{tabular}


Whole Cohort

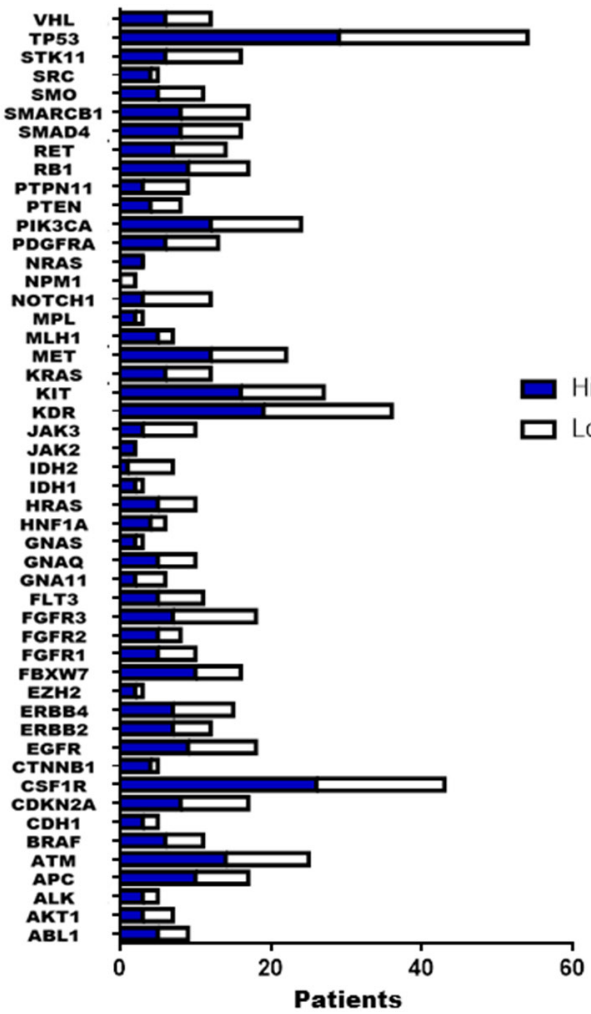

Low/Moderate risk

ligh Risk

Low/Moderate Risk

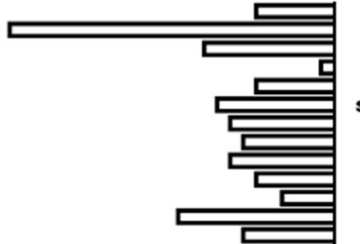

VHL

STK11

SMO

SMARCB
SMAD4

RET

RB1

PTPN11

PIKBCA

PIKGFRA

NRAS

NPM1

NOTCH1

MLH1

MET
KRAS

KIT

JAK3

JAK2

IDH1

HRAS

GNAS

GNAQ

FLT3

FGFR3

FGFR2

FBXW7

ERBB4
ERBB2

EGFR

CTNNB1
CSF1R

CDKN2A
CDH1

BRAF

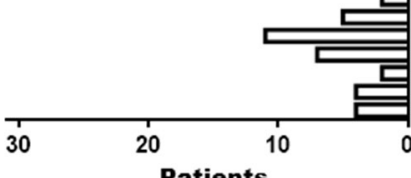

ATM
APC

ALK

ABL1
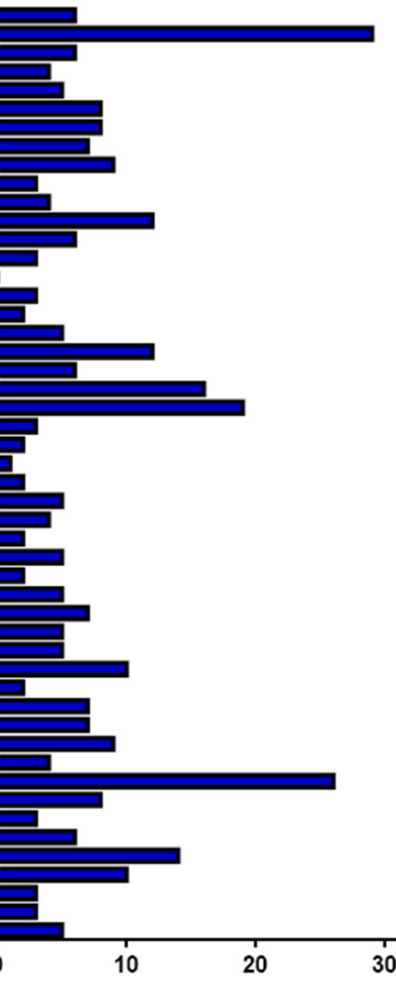

Patients

Figure 1: Summary of genetic variations identified by NGS. Non synonymous/regulative variations identified in the 50 cancer-associated genes with at least $10 \%$ of allelic frequency are summarized in figure. The blue blocks indicate patients with High risk of PCa-recurrence while the white blocks those patients with low/moderate risk.

Table 2: Main genetic variations identified in prostate cancer patients

\begin{tabular}{|c|c|c|c|c|c|c|c|c|c|c|}
\hline Gene & Chr & Position & Ref & Alt & Type & $\begin{array}{c}\text { AA } \\
\text { Change }\end{array}$ & SNP ID & COSMIC ID & $\begin{array}{l}\text { Patients } \\
\text { affected }\end{array}$ & $\begin{array}{l}\text { Corre- } \\
\text { lation }\end{array}$ \\
\hline CSF1R & chr5 & 149433596 & $\mathrm{~T}$ & G & UTR3 & NA & rs2066934 & NA & 42 & High Risk \\
\hline CSF1R & chr5 & 149433597 & G & A & UTR3 & NA & rs2066933 & NA & 42 & High Risk \\
\hline FGFR3 & chr4 & 1806131 & $\mathrm{~T}$ & $\mathrm{C}$ & $\begin{array}{c}\text { Non- } \\
\text { Synonymous }\end{array}$ & $\begin{array}{l}\text { p.F384L, } \\
\text { p.F386L }\end{array}$ & rs17881656 & $\begin{array}{c}\text { COSM724, } \\
\text { COSM1539830 }\end{array}$ & 5 & $\mathrm{~T} \leq 2 \mathrm{~b}$ \\
\hline FGFR3 & chr4 & 1807922 & G & A & intronic & NA & rs3135898 & NA & 11 & $\begin{array}{l}\text { High Risk, } \\
\quad \mathrm{T} \geq 2 \mathrm{c}\end{array}$ \\
\hline KDR & $\operatorname{chr} 4$ & 55972974 & $\mathrm{~T}$ & A & $\begin{array}{c}\text { Non- } \\
\text { Synonymous }\end{array}$ & p.Q472H & rs1870377 & COSM149673 & 28 & $\begin{array}{l}\text { Less } \\
\text { invasive } \\
\text { tumor }\end{array}$ \\
\hline MET & $\operatorname{chr} 7$ & 116340270 & G & A & $\begin{array}{c}\text { Non- } \\
\text { Synonymous }\end{array}$ & p.V378I & NA & COSM3411512 & 6 & $\begin{array}{l}\text { High Risk, } \\
\mathrm{T} \geq 2 \mathrm{c} \text {, short } \\
\text { recurrence } \\
\text { time }\end{array}$ \\
\hline TP53 & chr17 & 7579472 & G & $\mathrm{C}$ & $\begin{array}{c}\text { Non- } \\
\text { Synonymous }\end{array}$ & p.P72R & rs 1042522 & COSM250061 & 47 & $\begin{array}{l}\text { High Risk, } \\
\quad \mathrm{T} \geq 2 \mathrm{c}\end{array}$ \\
\hline
\end{tabular}




\section{NS GVs 5\% AF}

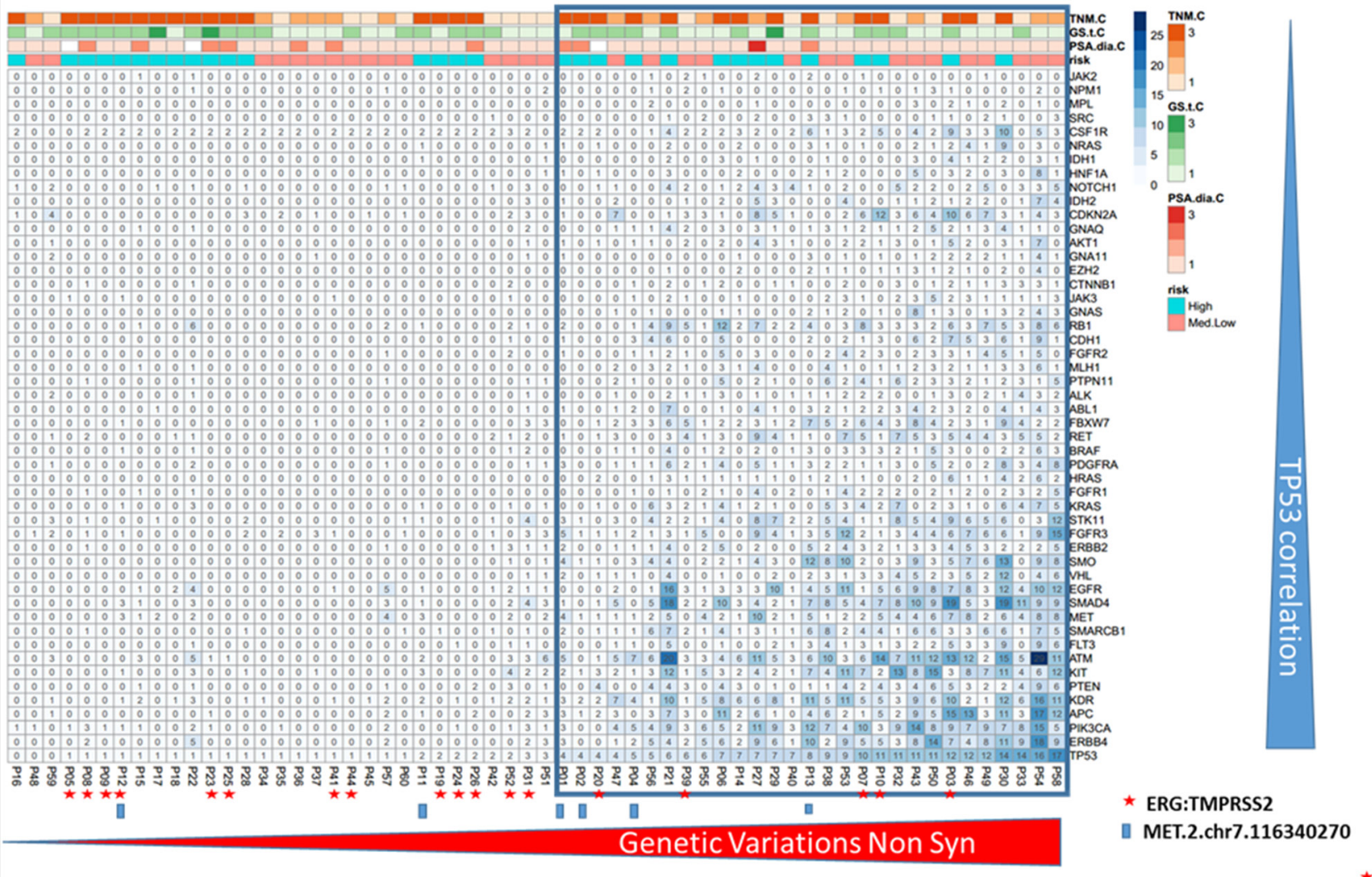

Figure 2: CHP2 genetic variability in prostate cancer. The panel shows the heatmap of PCa samples, including only the non synonymous/regulative variations at $\geq 5 \% \mathrm{AF}$. The $\geq 5 \%$ filter was used only for graphic display. The blue tiles identify variations and color intensity is proportional to the number of variations observed in each PCa sample and indicated within the tile. Independently by the risk class, the group of cases having several GVs in many genes was associated with high TP53 mutational rate. Furthermore, only in a small subgroup of these high-mutated patients, the TMPRSS2-ERG translocation was detected (red star).
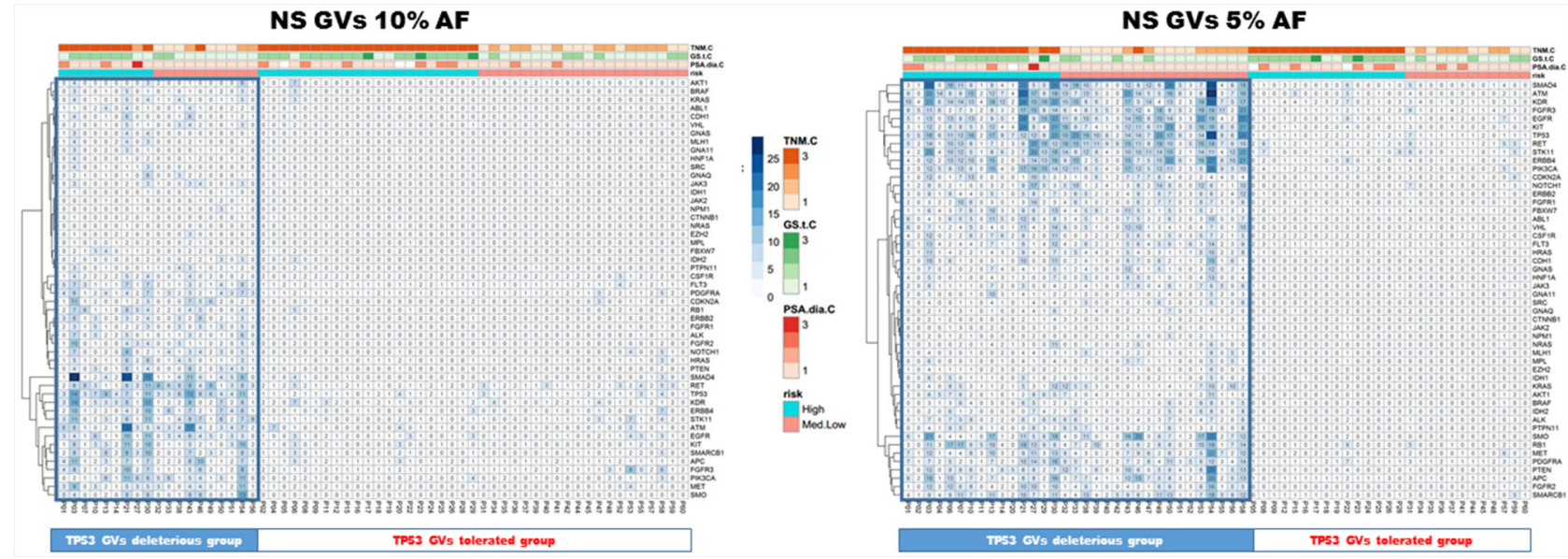

Figure 3: TP53 GVs deleterious correlate with high mutation rate patients. Both heatmaps represent PCa patients with only the non synonymous/regulative variations at $\geq 10 \%$ (left panel) or $\geq 5 \% \mathrm{AF}$ (right panel). Blue tiles contain the number of variations identified, visualized by proportional color intensity, observed in each PCa sample. The entire group of patients was clustered for "deleterious" or "tolerated" TP53 mutations, using a combination of PolyPhen-2 and SIFT software. In both panels, representing the applied AF filters of $\geq 10 \%$ and the $\geq 5 \%$, respectively, patients with a high mutation rate were often included in "TP53 GVs deleterious group". 
deleterious group" and only few of these tumors showed TMPRSS2:ERG translocation.

To highlight differences between HI and LM groups, the matrix of non-synonymous $\mathrm{GVs}(\mathrm{AF} \geq 10 \%)$ was also assessed by means of SAM-sequencing tools. This software allows detecting differences between two or more groups determining a false discovery rate (FDR) to increase robustness of data analyses. CSF1R GVs were associated to HI risk group and NOTCH1, IDH2, FGFR3 and STK11 often altered in LM groups (Figure 4, upper panel). Interestingly, some of these non-synonymous GVs were enriched in limited gene regions corresponding to specific protein domain (Figure 4, lower panel) [7]. GVs for the FGFR3 gene were consistently clustered in I-set domain, $P$-kinase Domain and between these two regions, as well as at the end of coding sequence for NOTCH1, in the middle of STK11 kinase domain and in IDH2 iso dh domain.

To assess the expression pattern of CHP2 genes the NGS RNA-sequencing analysis was tested. After normalization by AmpliSeqRNA plugin, 22 valid expression profiles for the $\mathrm{HI}$ and 29 for the LM group were obtained. SAM-sequencing software identified, between the $\mathrm{HI}$ and the LM groups, differentially expressed transcripts for FBXW7, JAK2, GNAQ (t-test $\mathrm{p}=0.001, \mathrm{p}=0.02$ and $\mathrm{p}=0.02$, respectively). No correlation between CHP2 RNA expression and clinical-pathological characteristics was identified. An association between TP53 mRNA low levels and "TP53 altered group" $\geq 5 \% \mathrm{AF}$ was observed $(\mathrm{p}=0.02)$.

\section{DISCUSSION}

In the last 10 years, NGS boosted biological and biomedical knowledge facilitating multi-gene mutational profiling using extremely small amounts of DNA, including that obtained by FFPE. The expanding application of NGS techniques has the potential for accurately mapping the type and extent of gene mutations in several solid tumors including $\mathrm{PCa}$. In this retrospective study, the feasibility of assessing mutational changes by NGS using FFPE tissue samples was investigated using

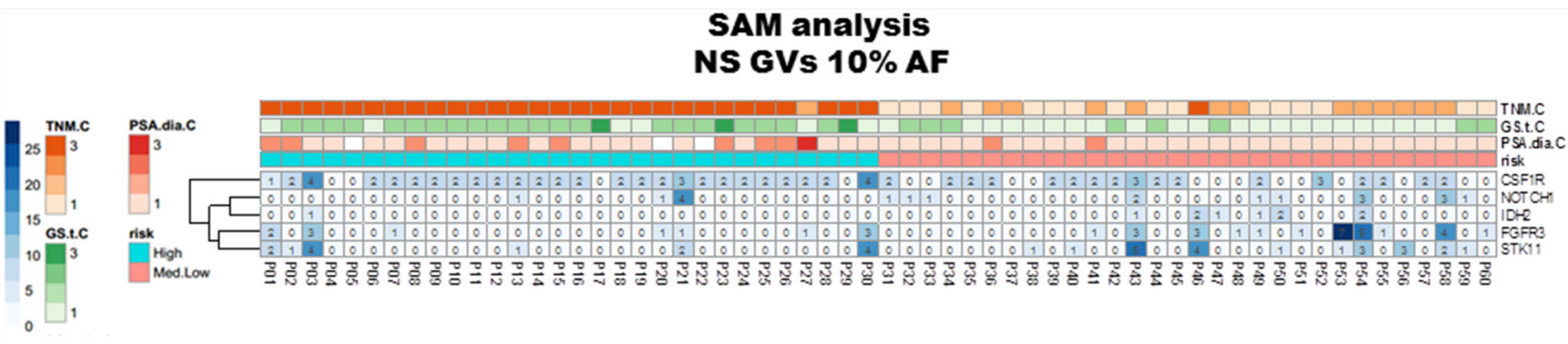

High Risk

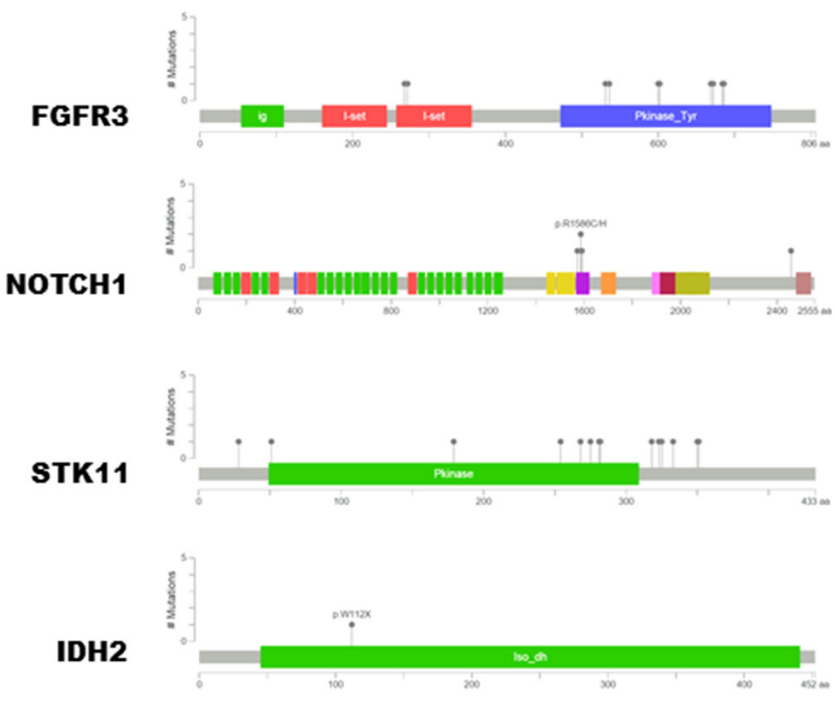

Low/Intermediate Risk
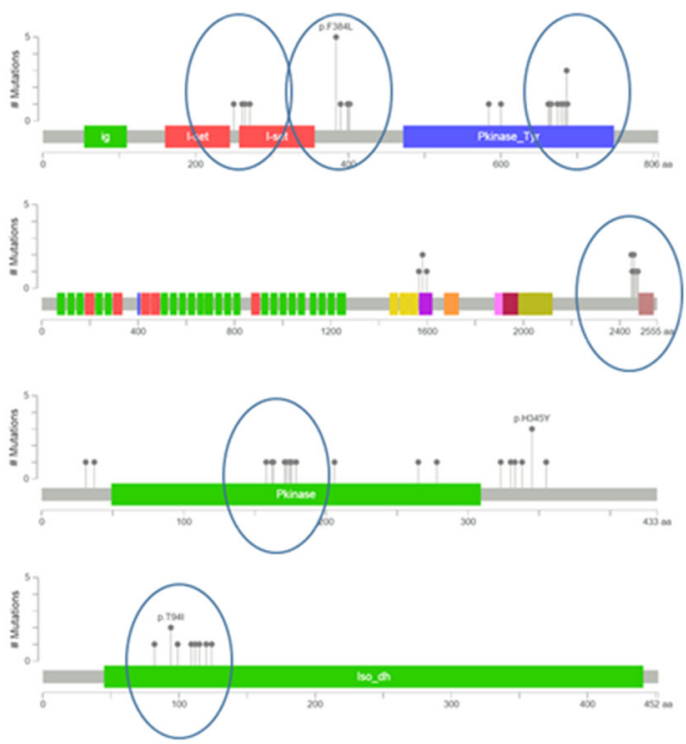

Figure 4: SAM analysis and protein domains localization of detected GVs. The upper panel summarizes the results elaborated by means of SAM software and visualized through heatmap including non synonymous/regulative variations at $\geq 10 \%$ AF. CSF1R GVs were mainly identified in HI risk patients, in contrast NOTCH1, IDH2, FGFR3 and STK11 GVs were often observed in LM group. The MutationMapper software, which identifies protein regions affected by corresponding GVs, reflects the protein localization of such nonsynonymous GVs, being enriched, in LM cluster, in limited and specific domains (lower right panel). 
a commercially available panel of key cancer-associated genes. Despite the limited number of samples included in this study, some peculiarities in PCa GVs profile were identified. An enrichment for GVs in a quite restricted number of genes including TP53, CSF1R, KDR, KIT, ATM, PIK3CA, MET, EGFR, FGFR3, ranging from $90 \%$ to $30 \%$ of the analyzed samples, were documented and most of these genes were previously associated with PCa.

Genetic alterations in TP53 were the most common GVs and this observation agrees with previously published data that since early ' 90 s documented TP53 mutations in PCa [8, 9]. Irrespective of risk stratification, we identified several alterations in this gene, some of which are already cancer-related and annotated in COSMIC database (Supplementary Table S1 ). In addition, patients with CHP2 high mutation rate display simultaneous "deleterious" TP53 mutations (Figure 2 and 3) and/or significant low levels of TP53 gene expression $(\mathrm{p}=0.02$, GVs $\geq 5 \%$ AF). These data support the hypothesis of a reduced activity/expression of TP53 protein in $\mathrm{PCa}$ and suggest for its role in PCa tumorigenesis or tumor progression, as already suggested by others $[9,10]$. High allelic variations at TP53 p.P72R, already identified in malignant pleural mesothelioma [11], were observed in PCa mainly in the HI risk group, suggesting its potential role as a risk factor. In agreement with our data, Zhang et al. showed that Caucasians with the Arg allele have an increased PCa risk [12]. A significant difference in the frequency of TP53 codon 72 variants between sporadic PCa and benign prostate hyperplasia was recently observed, implying that this polymorphism may have a role in tumor development [13]. In our study, we identified two SNPs in CSF1R gene, rs2066934 and rs2066933, mainly detected in HI risk group. Although these SNPs have been also recently reported in malignant pleural mesothelioma [11], scant information is available about these GVs. These two nucleotides trigger the 3'UTR region in a miRNA seed-complementary sequence, which could modulate response to imatinib by increasing CSF1R gene expression [14]. Two other studies which extensively explored NGS in advanced, castration resistant PCa did not detect any GVs in the CSF1R gene but differences in the disease setting and the NGS platforms used preclude any comparison $[5,6]$.

KIT p.M541L mutation, identified in about $30 \%$ of the tumors and without any relationship with the risk class, was already associated to clinical response to imatinib. In patients with aggressive fibromatosis harboring this mutation, a higher sensitivity to imatinib was initially observed but not confirmed in a subsequent study, possibly as the consequence of the rarity of this mutation in these rare tumors $[15,16]$. Patients with chronic eosinophilic leukemia positive for KIT p.M541L showed clinical response to low dose imatinib [17]. In preclinical studies in PCa cells imatinib, alone or in combination with other cytotoxic therapies, showed a significant treatment effect
[18-20]. Conversely, in clinical studies in patients with castration resistant $\mathrm{PCa}$ imatinib demonstrated only a modest activity [21-23]. These conflicting data between preclinical and clinical studies in PCa may be the result of a differential role of the CSF1R/KIT genetic alterations in patients and in cell lines. Our findings suggest additional studies testing the role of imatinib in genetically selected PCa patients.

The MET p.V378I mutation was detected in 6 tumors of the HI risk group and associated with early PCa recurrence following radical surgery (Table 2). Whereas the proto-oncogene MET has been associated with PCa, the specific variation MET p.V378I, included in COSMIC database (COSM3411512), has not been extensively investigated. C-Met expression increases in advanced stages of the disease and more frequently in patients with bone metastases [24, 25]. In addition, c-MET protein expression is higher in poorly differentiated PCa with low PSA levels [26]. An inverse relationship between Androgen Receptor (AR) and c-MET has been already demonstrated [27] suggesting that a reduction of AR activity through androgen ablation may increase the expression of c-MET, directly contributing to androgen insensitivity and favoring tumor aggressiveness. Several clinical trials with different c-MET inhibitors (cabozantinib, tivantinib and other multi-target kinase inhibitors), have been recently performed [28-30] or are ongoing (NCT01428219, NCT01703065, NCT01630590, NCT01834651, NCT01812668, NCT01683994, NCT01519414), but the available data did not show any significant impact of these inhibitors on overall survival. These negative results could reflect the genetic variability highlighted in our study and the c-MET mutational status may potentially considered as a stratification factor in future studies aimed at evaluating the role c-MET inhibitors.

The genetic alterations in NOTCH1, IDH2, FGFR3 and STK11 more frequently reported in the LM risk group are located in regions that could influence protein functionality. Additional studies are needed to assess if GVs identified may deregulate or influence the corresponding gene expression/function. Retrospective studies showed a correlation between FGFR3 mutations and the development of good prognosis superficial bladder carcinoma [31, 32]. Interestingly in PCa FGFR3 mutations were associated with low-grade tumors. The F386L polymorphism has been reported in association with lowgrade tumors and early disease stage [33] and in our series the FGFR3 p.F384L/p.F386L was associated with T<T2b patients $(p=0.004)$.

Several studies on PCa have investigated the association between TMPRSS2:ERG fusion gene and outcome reporting conflicting results [34]. In our study, the presence of this rearrangement was correlated with the risk of recurrence, being the fusion gene mostly detected in patients with a low mutation rate. This observation 
suggests an involvement of TMPRSS2:ERG fusion gene in $\mathrm{PCa}$ aggressiveness independent from the gain of mutations. A previous study indicated that TMPRSS2ERG gene fusion is a common event and occurs early in the development of invasive PCa [35]. Another study indicated that ERG gene alterations represent an initiating event that favors epithelial atypia and further progression to high-grade prostatic intraepithelial neoplasia and cancer [36].

After performing the DNA sequencing analyses, we also conducted an RNA sequencing analysis to determine gene expression of the 50 genes included in CHP2. We detected that FBXW7, GNAQ and JAK2 were over-expressed in the HI risk group without showing any correlation between gene expression and clinicalpathological characteristics. Additional investigation is needed to assess if these mRNA de-regulations may influence the protein expression and/or contribute to $\mathrm{PCa}$ development/progression.

We identified genetic markers potentially associated with disease pathogenesis, progression and response/ resistance to treatment. However the translation of these results to the development of clinical diagnostic tests and to patient stratification in clinical trial is critical. Significant challenges, such as intra-tumoral heterogeneity and multifocality in primary tumors, limits the application of genomic medicine in prostate cancer and hinder the generation of risk stratification tools that correlate clinical outcome with the genomic landscape. Large clinical trials are needed to prospectively validate the utility of genetic markers for the clinical decision making.

In conclusion, this is one of the first retrospective studies that tested the feasibility of NGS for PCa genetic characterization using FFPE archival material. Although the limited number of patients limits the statistical power of the analyses, the reported results are in agreement with previously published data suggesting a complex mutational pattern in $\mathrm{PCa}$. In addition, our data support the involvement of TP53, MET, FGFR3, CSF1R GVs in PCa, mainly influencing tumor progression or aggressiveness. Some of these GVs, such as CSFR1 SNPs or KIT p.M541L may potentially contribute, if data will be confirmed in larger studies, to customized treatments with targeted therapies.

\section{MATERIALS AND METHODS}

\section{Patients and tissue samples}

Sixty cases of localized or locally advanced PCa submitted to radical prostatectomy at San Luigi Gonzaga Hospital (Orbassano, Turin) between September 2003 and May 2009, with enough leftover FFPE tissue available and detailed clinical annotates were retrospectively extracted from an institutional clinical database. Based on PSA, GS and T, using the D'Amico criteria, tumors were categorized as high risk (HI, PSA $>20 \mathrm{ng} / \mathrm{ml}, \mathrm{GS}>7$, $\mathrm{T} 2 \mathrm{c}-\mathrm{T} 3, \mathrm{n}=30$ ) or low-intermediate risk (LM, low risk: PSA $<10 \mathrm{ng} / \mathrm{ml}, \mathrm{GS}<7$, T1-T2a; intermediate risk: PSA: 10-20 ng/ml, GS=7, T2b, n=30).

Informed consent was previously obtained from each patient and the Institutional Review Board approved the study. All samples were de-identified and cases anonymized by a pathology staff member not involved in the study.

All samples were reviewed and classified according to UICC criteria [37].

\section{RNA isolation from paraffin-embedded tissues and quantitative real-time PCR}

Serial $10 \mu \mathrm{m}$ sections were cut in RNase-free conditions. The specimens were stained with hematoxylineosin, representative tumor areas were identified and isolated by means of microdissection using a scalpel at a magnification of 100x. RNA isolation was performed using commercially available RNA extraction kits for paraffin material according to the manufacturer's instructions (High Pure RNA paraffine kit; Roche Applied Science, Germany).

Complementary DNA was transcribed using random hexamer primers (Roche Applied Science) and M-MLV reverse transcriptase (200 U/ml; Invitrogen, Carlsbad; CA) according to standard protocols.

Expression levels for all investigated genes and an internal reference gene ( $\beta$-actin) were assessed using a fluorescence-based real-time detection method (ABI PRISM 7900 Sequence Detection System-Taqman; Applied Biosystems, Foster City, CA,). Primers for $\beta$-actin and for androgen receptor have been previously reported [38, 39]. For androgen receptor and ERG:TMPRSS2 fusion gene TaqMan gene expression assays (AR: HS00171172_m1, TMPRSS2-ERG: HS003063375$\mathrm{ft}$ ) were diluted 1:20 with 1X Taqman Universal PCR Master Mix to a final volume of $20 \mu \mathrm{L}$ (all reagents from Applied Biosystems). Cycling conditions were $50^{\circ} \mathrm{C}$ for 2 minutes and $95^{\circ} \mathrm{C}$ for 10 minutes followed by 46 cycles at $95^{\circ} \mathrm{C}$ for 15 seconds and $60^{\circ} \mathrm{C}$ for 1 minute. Relative gene expression levels were expressed as unit less ratios between 2 measurements (genes of interest/internal reference gene). Total RNAs (Stratagene, La Jolla, CA) were used as control calibrators on each plate.

\section{Genomic DNA/total mRNA extraction and NGS}

Nucleic acids for NGS were obtained from tissues after manual microdissection with enrichment for at least $50 \%$ of neoplastic cells. Genomic DNA (gDNA) and total mRNA were extracted using AllPrep DNA/RNA FFPE Kit (Qiagen, Hilden, Germany) following the manufacturer's instructions. gDNA and mRNA were quantified using fluorometer Qubit platform (Invitrogen, Carlsbad, CA). 
NGS analyses were performed on the Ion Torrent Personal Genome Machine (PGM, Life Technologies, Grand Island, USA). Tumor samples were tested using a commercially available library kit (gDNA: Ion AmpliSeq Cancer Hotspot Panel v.2 (CHP2), mRNA: Ion AmpliSeq RNA Cancer Panel) to investigate 50 cancerassociated genes (See Supplementary Table S1 ). Each amplicon library was generated starting from $10 \mathrm{ng}$ of gDNA or mRNA, as indicated by the manufacturer, and barcoded with Ion Xpress Barcode Adaptors Kit (Life Technologies). DNA Library quantification was performed using the PCR quantification kit and the $7900 \mathrm{HT}$ real time PCR system (Life Technologies), diluted in nuclease-free water to obtain a final concentration of $100 \mathrm{pM}$. Emulsion PCR was performed on Ion PGM ${ }^{\mathrm{TM}}$ Template One Touch 2 system (Life Technologies). The quality of the emulsion PCRs was measured using the Qubit IonSphere Quality control kit (Life Technologies). IonSphere Particles with DNA were isolated and sequenced on Ion 316 Chip using the Ion PGM ${ }^{\mathrm{TM}}$ Sequencing $200 \mathrm{Kit}$ (Life Technologies). Only sample sequences with at least a quality score of AQ20 (1 misaligned base per 100 bases) were considered for further analyses.

\section{DNA target sequencing}

The inclusion criteria for the analyses mainly considered the coverage target for each sample and this value was set at a minimum average deep of 100 reads for each amplicon (whole coverage: $\min =18, \max =3875$, amplicons average $=1190$ ). Variant Caller plugin included in Torrent Suite Software v.4.2.1 was used to identify variations in target regions and genetic annotation was performed with Annovar software [40] (COSMIC database v.70, SNPs database v.138). Each of the identified genetic variation was coded according to "plus strand" of Human Genome assembly hg19. Some of the commonest genetic variations identified in the study were further validated and specific primers listed in CHP2 supplementary files were used for PCR. The quality of the resulting amplicons was checked by LabChip ${ }^{\circledR}$ GX (PerkinElmer, Waltham, MA, USA) and subsequently validated by Sanger sequencing. For the genetic variations in study, the correlation between Sanger and NGS was always $\geq 80 \%$.

\section{RNA target sequencing}

AmpliSeqRNA plugin included in Torrent Suite Software v.4.2.1 was used to normalize expression levels of each amplicon in the RNA-sequencing analysis. Differentially expressed/mutated genes between the HI and LM risk groups were identified using the RNA-seq version of Significance Analysis of Microarray (SAMseq) included in the R package "samr". The significant differential expression levels were subsequently tested in qPCR analysis.

\section{Statistical analysis}

Statistical correlation between gene variations with allelic frequency (AF) $\geq 10 \%$ and clinical-pathological features were investigated by Fisher exact test.

Time to progression (TTP) was defined as the time from the prostatectomy until the first evidence of disease progression, defined as confirmed PSA increase above 0.2 $\mathrm{ng} / \mathrm{ml}$. The $\log$ rank test was used to assess differences between groups. The Cox proportional hazards regression model was performed to analyze independent prognostic factors and TTP. Only the variables that were found to be significant in the univariate analyses $(\mathrm{p}<0.05)$ were entered into the multivariable analysis to determine the most significant factors for predicting disease outcome. Statistical analysis was elaborated using R statistical software [41].

\section{CONFLICTS OF INTEREST}

Professor Giorgio V. Scagliotti has consulting role in Eli Lilly and received honoraria from Eli Lilly, Astra Zeneca, Roche, Pfizer and Clovis Oncology; Professor Mauro Papotti received honoraria from Boehringer, Ely lilly, Clovis Oncology and Novartis. All other authors have no conflict of interests to declare.

\section{GRANT SUPPORT}

None.

\section{REFERENCES}

1. Siegel RL, Miller KD and Jemal A. Cancer statistics, 2015. CA Cancer J Clin. 2015; 65:5-29.

2. D'Amico AV, Whittington R, Malkowicz SB, Schultz D, Blank K, Broderick GA, Tomaszewski JE, Renshaw AA, Kaplan I, Beard CJ and Wein A. Biochemical outcome after radical prostatectomy, external beam radiation therapy, or interstitial radiation therapy for clinically localized prostate cancer. JAMA. 1998; 280:969-974.

3. Yadav SS, Li J, Lavery HJ, Yadav KK and Tewari AK. Next-generation sequencing technology in prostate cancer diagnosis, prognosis, and personalized treatment. Urologic oncology. 2015; 33:267 e261-267 e213.

4. Culig Z. TMPRSS:ERG fusion in prostate cancer: from experimental approaches to prognostic studies. European urology. 2014; 66:861-862.

5. Robinson D, Van Allen EM, Wu YM, Schultz N, Lonigro RJ, Mosquera JM, Montgomery B, Taplin ME, Pritchard CC, Attard G, Beltran H, Abida W, Bradley RK, Vinson J, Cao X, Vats P, et al. Integrative clinical genomics of advanced prostate cancer. Cell. 2015; 161:1215-1228.

6. Barbieri CE, Baca SC, Lawrence MS, Demichelis F, Blattner M, Theurillat JP, White TA, Stojanov P, Van Allen E, Stransky N, Nickerson E, Chae SS, Boysen G, Auclair 
D, Onofrio RC, Park K, et al. Exome sequencing identifies recurrent SPOP, FOXA1 and MED12 mutations in prostate cancer. Nat Genet. 2012; 44:685-689.

7. Vohra S and Biggin PC. Mutationmapper: a tool to aid the mapping of protein mutation data. PloS one. 2013; 8:e71711.

8. Isaacs WB, Bova GS, Morton RA, Bussemakers MJ, Brooks JD and Ewing CM. Molecular biology of prostate cancer progression. Cancer surveys. 1995; 23:19-32.

9. Navone NM, Troncoso P, Pisters LL, Goodrow TL, Palmer JL, Nichols WW, von Eschenbach AC and Conti CJ. p53 protein accumulation and gene mutation in the progression of human prostate carcinoma. Journal of the National Cancer Institute. 1993; 85:1657-1669.

10. Ecke TH, Schlechte HH, Schiemenz K, Sachs MD, Lenk SV, Rudolph BD and Loening SA. TP53 gene mutations in prostate cancer progression. Anticancer Res. 2010; 30:1579-1586.

11. Lo Iacono M, Monica V, Righi L, Grosso F, Libener R, Vatrano S, Bironzo P, Novello S, Musmeci L, Volante M, Papotti $M$ and Scagliotti GV. Targeted next-generation sequencing of cancer genes in advanced stage malignant pleural mesothelioma: a retrospective study. Journal of thoracic oncology. 2015; 10:492-499.

12. Zhang J, Zhuo WL, Zheng $\mathrm{Y}$ and Zhang YS. Polymorphisms of TP53 codon 72 with prostate carcinoma risk: a meta-analysis. Medical oncology. 2010; 27:540-546.

13. Babaei F, Ahmadi SA, Abiri R, Rezaei F, Naseri M, Mahmoudi M, Nategh R and Mokhtari Azad T. The TP53 Codon 72 Polymorphism and Risk of Sporadic Prostate Cancer among Iranian Patients. Iranian journal of public health. 2014; 43:453-459.

14. Manikandan M and Munirajan AK. Single nucleotide polymorphisms in microRNA binding sites of oncogenes: implications in cancer and pharmacogenomics. Omics. 2014; 18:142-154.

15. Dufresne A, Bertucci F, Penel N, Le Cesne A, Bui B, Tubiana-Hulin M, Ray-Coquard I, Cupissol D, Chevreau C, Perol D, Goncalves A, Jimenez M, Bringuier PP and Blay JY. Identification of biological factors predictive of response to imatinib mesylate in aggressive fibromatosis. Br J Cancer. 2010; 103:482-485.

16. Dufresne A, Alberti L, Brahmi M, Kabani S, Philippon H, Perol D and Blay JY. Impact of KIT exon 10 M541L allelic variant on the response to imatinib in aggressive fibromatosis: analysis of the desminib series by competitive allele specific Taqman PCR technology. BMC Cancer. 2014; 14:632.

17. Iurlo A, Gianelli U, Beghini A, Spinelli O, Orofino N, Lazzaroni F, Cambiaghi S, Intermesoli T, Rambaldi A and Cortelezzi A. Identification of kit(M541L) somatic mutation in chronic eosinophilic leukemia, not otherwise specified and its implication in low-dose imatinib response. Oncotarget. 2014; 5:4665-4670. doi: 10.18632/oncotarget.1941.
18. Cardoso HJ, Vaz CV, Correia S, Figueira MI, Marques R, Maia CJ and Socorro S. Paradoxical and contradictory effects of imatinib in two cell line models of hormonerefractory prostate cancer. The Prostate. 2015; 75:923-935.

19. Kimura Y, Inoue K, Abe M, Nearman J and BaranowskaKortylewicz J. PDGFRbeta and HIF-1alpha inhibition with imatinib and radioimmunotherapy of experimental prostate cancer. Cancer biology \& therapy. 2007; 6:1763-1772.

20. Kubler HR, van Randenborgh H, Treiber U, Wutzler S, Battistel C, Lehmer A, Wagenpfeil S, Hartung R and Paul $R$. In vitro cytotoxic effects of imatinib in combination with anticancer drugs in human prostate cancer cell lines. The Prostate. 2005; 63:385-394.

21. Mathew P, Thall PF, Jones D, Perez C, Bucana C, Troncoso P, Kim SJ, Fidler IJ and Logothetis C. Platelet-derived growth factor receptor inhibitor imatinib mesylate and docetaxel: a modular phase I trial in androgen-independent prostate cancer. J Clin Oncol. 2004; 22:3323-3329.

22. Lipton A, Campbell-Baird C, Harvey H, Kim C, Demers $\mathrm{L}$ and Costa L. Phase I trial of zoledronic acid + imatinib mesylate (Gleevec) in patients with bone metastases. Am J Clin Oncol. 2010; 33:75-78.

23. Nabhan C, Villines D, Valdez TV, Tolzien K, Lestingi TM, Bitran JD, Christner SM, Egorin MJ and Beumer JH. Phase I study investigating the safety and feasibility of combining imatinib mesylate (Gleevec) with sorafenib in patients with refractory castration-resistant prostate cancer. Br J Cancer. 2012; 107:592-597.

24. Knudsen BS and Edlund M. Prostate cancer and the met hepatocyte growth factor receptor. Adv Cancer Res. 2004; 91:31-67.

25. Varkaris A, Corn PG, Gaur S, Dayyani F, Logothetis CJ and Gallick GE. The role of HGF/c-Met signaling in prostate cancer progression and c-Met inhibitors in clinical trials. Expert Opin Investig Drugs. 2011; 20:1677-1684.

26. Humphrey PA, Zhu X, Zarnegar R, Swanson PE, Ratliff TL, Vollmer RT and Day ML. Hepatocyte growth factor and its receptor (c-MET) in prostatic carcinoma. The American journal of pathology. 1995; 147:386-396.

27. Verras M, Lee J, Xue H, Li TH, Wang Y and Sun Z. The androgen receptor negatively regulates the expression of c-Met: implications for a novel mechanism of prostate cancer progression. Cancer research. 2007; 67:967-975.

28. Yap TA, Olmos D, Brunetto AT, Tunariu N, Barriuso J, Riisnaes R, Pope L, Clark J, Futreal A, Germuska M, Collins D, deSouza NM, Leach MO, Savage RE, Waghorne C, Chai F, et al. Phase I trial of a selective c-MET inhibitor ARQ 197 incorporating proof of mechanism pharmacodynamic studies. J Clin Oncol. 2011; 29:1271-1279.

29. Dahut WL, Scripture C, Posadas E, Jain L, Gulley JL, Arlen PM, Wright JJ, Yu Y, Cao L, Steinberg SM, Aragon-Ching JB, Venitz J, Jones E, Chen CC and Figg WD. A phase II clinical trial of sorafenib in androgen-independent prostate cancer. Clinical cancer research. 2008; 14:209-214. 
30. Lee RJ, Saylor PJ, Michaelson MD, Rothenberg SM, Smas ME, Miyamoto DT, Gurski CA, Xie W, Maheswaran S, Haber DA, Goldin JG and Smith MR. A dose-ranging study of cabozantinib in men with castration-resistant prostate cancer and bone metastases. Clinical cancer research. 2013; 19:3088-3094.

31. van Rhijn BW, Lurkin I, Radvanyi F, Kirkels WJ, van der Kwast TH and Zwarthoff EC. The fibroblast growth factor receptor 3 (FGFR3) mutation is a strong indicator of superficial bladder cancer with low recurrence rate. Cancer research. 2001; 61:1265-1268.

32. Hernandez S, Lopez-Knowles E, Lloreta J, Kogevinas M, Jaramillo R, Amoros A, Tardon A, Garcia-Closas R, Serra C, Carrato A, Malats N and Real FX. FGFR3 and Tp53 mutations in T1G3 transitional bladder carcinomas: independent distribution and lack of association with prognosis. Clinical Cancer Research. 2005; 11:5444-5450.

33. Hernandez S, de Muga S, Agell L, Juanpere N, Esgueva R, Lorente JA, Mojal S, Serrano S and Lloreta J. FGFR3 mutations in prostate cancer: association with low-grade tumors. Modern pathology. 2009; 22:848-856.

34. Bostrom PJ, Bjartell AS, Catto JW, Eggener SE, Lilja H, Loeb S, Schalken J, Schlomm T and Cooperberg MR. Genomic Predictors of Outcome in Prostate Cancer. European urology. 2015.

35. Perner S, Mosquera JM, Demichelis F, Hofer MD, Paris PL, Simko J, Collins C, Bismar TA, Chinnaiyan AM, De Marzo AM and Rubin MA. TMPRSS2-ERG fusion prostate cancer: an early molecular event associated with invasion. The American journal of surgical pathology. 2007; 31:882-888.

36. Clark J, Attard G, Jhavar S, Flohr P, Reid A, De-Bono J, Eeles R, Scardino P, Cuzick J, Fisher G, Parker MD, Foster CS, Berney D, Kovacs G and Cooper CS. Complex patterns of ETS gene alteration arise during cancer development in the human prostate. Oncogene. 2008; 27:1993-2003.

37. Sobin LHG, M.; Wittekind, C. (2009). TNM classification of malignant tumors. UICC International Union Against Cancer.

38. Ceppi P, Volante M, Saviozzi S, Rapa I, Novello S, Cambieri A, Lo Iacono M, Cappia S, Papotti $M$ and Scagliotti GV. Squamous cell carcinoma of the lung compared with other histotypes shows higher messenger RNA and protein levels for thymidylate synthase. Cancer. 2006; 107:1589-1596.

39. Jernberg E, Thysell E, Bovinder Ylitalo E, Rudolfsson S, Crnalic S, Widmark A, Bergh A and Wikstrom P. Characterization of prostate cancer bone metastases according to expression levels of steroidogenic enzymes and androgen receptor splice variants. PloS one. 2013; 8:e77407.

40. Wang K, Li M and Hakonarson H. ANNOVAR: functional annotation of genetic variants from high-throughput sequencing data. Nucleic acids research. 2010; 38:e164.

41. Team RDC. R: A Language and Environment for Statistical Computing. R Foundation for Statistical Computing. 2011. 